DOI: https://doi.org/10.15688/lc.jvolsu.2019.3.9

UDC 346

Submitted: 14.05.2019

LBC 67.408

Accepted: 15.06.2019

\title{
THE LEGISLATIVE REGULATION OF THE STATUS OF JOINT VENTURES IN THE USSR
}

\author{
Tatiana K. Krasilnikova \\ International Law Institute's Volzhsky Branch, Volzhsky, Russian Federation
}

Introduction: the paper is devoted to the joint ventures, international economic associations established and operating in the territory of the USSR. It is one of the first studies in the modern legal literature devoted to the analysis of the Soviet legislation determining the status of these types of economic entities. The aim of the study is to determine the legal nature of the joint venture as a legal entity, to identify the features of its legal capacity from the perspective of the civil law theory and practice. Results: the main problems that arise in the creation and operation of joint ventures, as well as the existing gaps in the Soviet legal space in the mechanism of the legal regulation of the organization and activities of entities with foreign participation are revealed. The peculiarity of the policy of the Soviet state in relation to business corporations, including joint ventures and international business associations, was a combination of administrative, legal and civil law methods of regulating their organization and activities.

Key words: corporations, joint ventures, joint economic associations, international economic organizations, legal entity.

Citation. Krasilnikova T.K. The Legislative Regulation of the Status of Joint Ventures in the USSR. Legal Concept, 2019, vol. 18, no. 3, pp. 61-67. (in Russian). DOI: https://doi.org/10.15688/lc.jvolsu.2019.3.9

УДК 346

Дата поступления статьи: 14.05.2019

ББК 67.408

Дата принятия статьи: 15.06.2019

\section{ЗАКОНОДАТЕЛЬНОЕ РЕГУЛИРОВАНИЕ СТАТУСА СОВМЕСТНЫХ ПРЕДПРИЯТИЙ В СССР}

\section{Татьяна Константиновна Красильникова}

Международный юридический институт (Волжский филиал), г. Волжский, Российская Федерация

Введение: данная статья посвящена совместным предприятиям, международным хозяйственным объединениям, создаваемым и действующим на территории СССР. Она представляет собой одно из первых в нашей современной юридической литературе исследований, посвященных анализу советского законодательства, определяющего статус данных видов хозяйствующих субъектов. Целью работы является определение юридической природы совместного предприятия как юридического лица, выявление особенностей его правоспособности с позиции цивилистической теории и практики. Для достижения цели использовались такие методы научного познания, как историко-правовой, сравнительный и формально-юридический. Результаты: выявлены основные проблемы, возникающие при создании и деятельности совместных предприятий, а также отмечены имеющиеся в советском правовом пространстве пробелы в механизме правового регулирования организации и деятельности субъектов с иностранным участием. Выводы: совместные предприятия и международные объединения можно рассматривать и как форму международного экономического сотрудничества, и как форму привлечения иностранных инвестиций, и как форму организации хозяйственной деятельности. Особенность политики Советского государства в отношении корпораций, включая совместные предприятия и международные хозяйственные объединения, заключалась в сочетание административно-правовых и гражданскоправовых методов регулирования их организации и деятельности.

Ключевые слова: корпорации, совместные предприятия, совместные хозяйственные объединения, международные хозяйственные организации, юридическое лицо. 


\section{ТЕОРИЯ И ПРАКТИКА ГОСУДАРСТВЕННО-ПРАВОВОГО РАЗВИТИЯ}

Цитирование. Красильникова Т. К. Законодательное регулирование статуса совместных предприятий в CCCP // Legal Concept = Правовая парадигма. -2019 . - T. 18, № 3. - C. 61-67. - DOI: https://doi.org/10.15688/ lc.jvolsu.2019.3.9

\section{Введение}

Институт корпорации в советский период подвергся серьезным трансформациям, тем не менее отдельные принципы корпоративного управления были заимствованы новыми институтами - различного рода производственными комплексами, совместными предприятиями.

Ранее в советской юридической литературе рассматривались общие вопросы проблематики различных организационных форм совместной деятельности, смешанных обществ, совместных предприятий и, прежде всего, международных хозяйственных объединений стран - членов СЭВ (труды А.Б. Братченко [1], Н.Н. Вознесенской [2; 3], Н.В. Миронова [8], А.Г. Санникова [14], П.С. Смирнова [15], Е.Г. Яковенко [17]). Правовые вопросы совместных предприятий, действующих в СССР, изучались главным образом в историческом аспекте. И это было естественно, поскольку на территории СССР с начала 30-х гг. до 1987 г. совместные предприятия не создавались. К сожалению, современная отечественная юриспруденция не дает какой-либо оценки деятельности данных хозяйствующих субъектов.

В имеющейся отечественной юридической литературе остается не решенным вопрос: считать или нет международные хозяйственные объединения, совместные предприятия, действующие в СССР, корпоративными объединениями и какая организационно-правовая форма в отношении их могла быть применима.

Задачей данного исследования является формирование целостного научного представления о совместных предприятиях и международных хозяйственных объединениях как корпоративных организациях, об их месте в системе советского права.

Правовые основы организации и деятельности совместных предприятий и международных объединений как хозяйствующих субъектов в СССР

Понятие «совместное предприятие» в юридической науке обозначает предприя- тие с долевым участием иностранных инвестиций.

В истории Советского государства вопрос о деятельности на территории страны совместных предприятий и международных объединений с участием иностранного капитала возник в начале 20-х годов в период введения в стране новой экономической политики. Это было время оживления и развития в экономике товарно-денежных отношений.

Согласно Постановлению Президиума ВЦИК «О внешней торговле» от 13 марта 1922 г. Народному комиссариату внешней торговли предоставлялось право с утверждения Совета труда и обороны (СТО) организовывать акционерные общества с участием иностранного капитала для осуществления экспортно-импортных операций и для производства экспортных товаров [9, ст. 266]. При этом в комбинированных акционерных обществах советская сторона должна была иметь не менее $51 \%$ акционерного капитала [6, с. 54]. На 1 января 1925 г. в стране насчитывалось 52 смешанных общества, из них 12 с иностранным капиталом [13, с. 19-24].

В начале 30 -х годов подавляющее число смешанных обществ на территории СССР прекратили свое существование.

Законодатель впервые раскрыл термин «совместное предприятие» в Законе РСФСР «Об иностранных инвестициях в РСФСР» от 4 июля 1991 г., хотя он широко использовался в юридической практике конца 80-х годов [4]. Именно тогда был взят курс на ускорение социально-экономического развития страны и приняты нормативно-правовые акты о совместных предприятиях с участием иностранного капитала $[10 ; 11]$.

Закон СССР «О государственном предприятии (объединении)» от 30 июня 1987 г. прямо предусматривал участие советских предприятий в деятельности совместных предприятий, международных объединений и организаций. В нем говорилось, что предприятие осуществляло экономические связи с фирмами капиталистических и развивающихся стран на принципах взаимовыгодности и 
равноправия и что основными формами развития таких связей являлись производственная и научно-техническая кооперация на долгосрочной и сбалансированной основе, а также создание совместных предприятий [5, ст. 285, п. 3].

Совместные предприятия с участием фирм капиталистических и развивающихся стран не относились к разряду государственных социалистических предприятий. При этом, безусловно, с точки зрения их правового статуса совместные предприятия, расположенные на территории СССР, считались субъектами права, находящимися под полной юрисдикцией Советского Союза [12, с. 63].

С позиции экономической науки совместное предприятие - это единый комплекс имущественных и людских факторов производства. С позиции же советского права именно предприятие признавалось юридическим лицом, а не организация, в ведении которой оно могло находиться (например, торговое товарищество). С позиции советского законодателя предприятие рассматривалось как субъект, а не как объект права.

Советский Союз и другие социалистические страны были пионерами в применении концепции юридического лица в отношении предприятий, в капиталистических же странах в качестве юридических лиц выступали торговые товарищества и хозяйственные общества. Предприятия же, принадлежащие торговым товариществам и обществам, находились на положении объектов права.

Согласно ст. 12 Основ гражданского законодательства СССР и союзных республик, а также согласно соответствующим статьям ГК союзных республик юридическое лицо могло вступать в те правоотношения, которые соответствовали определенной его уставом цели, в их число входили и те правоотношения, которые косвенно способствовали осуществлению стоящих перед юридическим лицом задач. На такой же позиции стояла и арбитражная практика.

Указанные положения полностью были применимы и к совместным предприятиям. «Устав, - говорилось в п. 7 Постановления Совета Министров СССР № 49, - определяет предмет и цели деятельности предприятия». В рамках реализации этих целей совместные предприятия вправе были совершать любые сделки и иные действия, предусмотренные законом, включая экспортные и импортные операции на международном рынке.

В п. 18 Постановления № 49 был закреплен принцип раздельной имущественной ответственности совместного предприятия и его участников по обязательствам совместного предприятия.

Известно, что в отношении имущества советских кооперативных и общественных организаций применялся режим права собственности, в отношении имущества государственных предприятий, объединений, организаций - режим права оперативного управления. В отношении же имущества совместных предприятий в законе вопрос оставался открытым. «Совместное предприятие, - говорилось в п. 15 Постановления № 49, - осуществляет согласно советскому законодательству владение, пользование и распоряжение своим имуществом в соответствии с целями своей деятельности и назначением имущества». Но о том, какое в совокупности право составляли названные правомочия, ничего не было сказано.

Таким образом, имущество совместных предприятий, за исключением объектов исключительной собственности государства (земля, леса, недра, воды), которые могли передаваться совместным предприятиям в качестве вклада советских участников в пользование, и другого имущества, арендуемого ими, должно было находиться у них на праве собственности.

Постановление Совета Министров СССР № 49 о совместных предприятиях на территории СССР предусматривало важнейшие правовые принципы организации и функционирования указанной формы сотрудничества в условиях советской экономики. Данный правовой акт определял, во-первых, разрешительный порядок учреждения совместных предприятий на территории СССР. Вовторых, устанавливал принцип применения к совместным предприятиям национального (то есть советского) права. В-третьих, в нем был заложен принцип преимущественно договорного, а не законодательного регулирования отношений сотрудничества в форме совместных предприятий. 


\section{ТЕОРИЯ И ПРАКТИКА ГОСУДАРСТВЕННО-ПРАВОВОГО РАЗВИТИЯ}

Вопросы создания на территории СССР совместных предприятий решались министерствами, ведомствами СССР и правительственными органами союзных республик. Права юридического лица данные предприятия приобретали с момента регистрации их учредительных документов Министерством финансов СССР.

Организационно-правовая форма совместных предприятий была схожа с широко распространенными в зарубежных странах обществами с ограниченной ответственностью. Совместное предприятие отвечало по своим обязательствам всем принадлежащим ему имуществом. СССР и участники совместного предприятия не отвечали по его обязательствам, а совместное предприятие не отвечало по обязательствам своих участников [11, ст. 18].

Таким образом, под совместными предприятиями следовало понимать советские юридические лица, учрежденные на территории СССР на основе договора путем вкладов участников в соответствии с советским законодательством и международными договорами СССР в качестве коллективных образований, участниками которых являлись субъекты права различных государств, в целях осуществления производственной, научно-технической и иной хозяйственной деятельности как в СССР, так и за его пределами, обладающие обособленным имуществом и несущие самостоятельную ответственность по своим обязательствам.

От совместных предприятий следовало отличать международные объединения и совместные организации. Два последних понятия применялись в советском законодательстве исключительно для обозначения форм сотрудничества стран - членов СЭВ. Международные объединения создавались для того, чтобы координировать деятельность их участников в различных областях народного хозяйства. Участники такого объединения могли объединять свое имущество для осуществления совместной хозяйственной деятельности.

Совместные организации могли создаваться для осуществления научно-исследовательской, проектно-конструкторской или иной деятельности. Таким образом, критерием от- несения к совместным предприятиям или к совместным организациям служил характер их деятельности.

Имелись особенности в организации и деятельности совместных предприятий и международных объединений. Постановлением Совета министров СССР № 48 регулировался порядок создания и деятельности совместных предприятий с участием организаций стран - членов СЭВ, а Постановлением Совета министров СССР № 49 - совместных предприятий с участием фирм капиталистических и развивающихся стран. Сравнение содержания этих двух постановлений показывает, что при наличии общих, одинаковых положений по ряду вопросов имелись и существенные различия. Так, по Постановлению № 48 совместные предприятия с участием стран - членов СЭВ создавались на основе межгосударственных или межправительственных договоров СССР (п. 3). По Постановлению № 49 предприятия создавались исключительно на основе договоров, заключаемых участниками таких предприятий, то есть на основе хозяйственных договоров (п. 1).

Постановление № 48 предусматривало, что участниками международного объединения могли быть как юридические лица, так и органы государственного управления СССР и других стран (п. 6). Участниками совместного предприятия по Постановлению № 49 (п. 4) могли быть только юридические лица: советские предприятия (объединения и другие организации) и иностранные фирмы (корпорации и другие организации).

Постановление № 48 не устанавливало какого-либо обязательного соотношения долей участников. В нем лишь говорилось (п. 27), что размер этих долей определялся учредительными документами. Постановление № 49 устанавливало, что доля участия Советского государства в уставном капитале совместного предприятия должна составлять не менее половины этого капитала (п. 5).

В отношении собственности Постановление № 48 указывало на то, что совместное предприятие осуществляло свою деятельность «на основе общей социалистической собственности» (п. 2, 25). Совместное предприятие осуществляло правомочия по владению, пользованию и распоряжению своим 
имуществом «в соответствии с целями своей деятельности» (п. 10). В Постановлении № 49 о характере собственности ничего не говорилось.

\section{Выводы}

Введение механизма нормативного регулирования создания и функционирования совместных предприятий и международных хозяйственных объединений являлось важнейшей предпосылкой возникновения новых для советской экономики хозяйственных структур и субъектов хозяйственной деятельности.

Применение этой формы Советским Coюзом было ограниченным, что не давало возможности использовать заложенные в ней преимущества, одним из которых являлось получение иностранной передовой технологии и навыков в управлении производством.

\section{Заключение}

Совместные предприятия и международные объединения можно рассматривать в трех аспектах, а именно: как форму международного экономического сотрудничества, как форму привлечения иностранных инвестиций и как форму организации конкретной хозяйственной деятельности. Совместные предприятия и международные объединения являлись более сложной, но и более эффективной формой сотрудничества, предполагающей более глубокие и тесные связи партнеров. Понимание совместного предприятия в целом соответствовало той концепции, которая получила распространение в других странах. Поэтому о совместных предприятиях можно было говорить как о единой форме сотрудничества. Такого рода сотрудничество заключалось «в объединении капиталов, принадлежащих предприятиям различных стран, в совместном управлении ими, а также в совместном несении убытков и в распределении прибыли пропорционально участию каждого в капитале» [7, с. 83]. Указанная сущность совместного предприятия, будучи опосредствованной правом и отраженной в его правовом устройстве, создала те особенности, которые отличали его от всех иных форм международного экономического сотрудничества.

\section{СПИСОК ЛИТЕРАТУРЫ}

1. Братченко, А. Б. Совместные предприятия / А. Б. Братченко. - М. : Знание, 1989. - 63 с.

2. Вознесенская, Н. Н. Правовые формы совместного предпринимательства и практика СССР / Н. Н. Вознесенская // Советское государство и право. -1985 . - № 3. - С. 59-66.

3. Вознесенская, Н. Н. Совместные предприятия с участием фирм капиталистических и развивающихся стран на территории СССР / Н. Н. Вознесенская // Советское государство и право. - 1988. № 1. - С. 117-125.

4. Закон РСФСР «Об иностранных инвестициях в РСФСР» от 4 июля 1991 года // Ведомости Съезда народных депутатов РСФСР и Верховного Совета РСФСР. - 1991. - № 29. - Ст. 1008.

5. Закон СССР «О государственном предприятии (объединении)» от 30 июня 1987 г. // Ведомости Верховного Совета СССР. - 1987. - № 26. CT. 285.

6. Красильникова, Т. К. Административная регламентация организации и деятельности корпораций и применение мер уголовных репрессий в СССР в 20-е годы XX века / Т. К. Красильникова // Вестник Волгоградского государственного университета. Серия 5, Юриспруденция. - 2012. № 1 (16). - С. 53-56.

7. Красильникова, Т. К. Совместное предприятие и международные хозяйственные объединения в системе советского права / Т. К. Красильникова // Образование и право. - 2018. - № 12. - С. 78-83.

8. Миронов, Н. В. Правовой статус совместных хозяйственных организаций стран - членов СЭВ на территории СССР / Н. В. Миронов // Советское государство и право. - 1984. - № 3. - С. 45-51.

9. Постановление Президиума ВЦИК «О внешней торговле» от 13 марта 1922 года // СУ РСФСР. 1922. - № 24.

10. Постановление Совета Министров СССР от 13 января 1987 г. № 48 «О порядке создания на территории СССР и деятельности совместных предприятий, международных объединений и организаций СССР и других стран СЭВ» // СП СССР. - 1987. № 8. - Ст. 38 .

11. Постановление Совета Министров СССР от 13 января 1987 г. № 49 «О порядке создания на территории СССР и деятельности совместных предприятий с участием советских организации и фирм капиталистических и развивающихся стран» // СП CCCP. - 1987. - № 9. - Ст. 40.

12. Правовое положение совместных предприятий на территории СССР / отв. ред.: М. М. Богуславский, А. А. Рубанов, М. М. Славин. - М. : Академия наук СССР, Институт государства и права, 1988. $-172 \mathrm{c}$. 
13. Правовые формы научно-технического и промышленного сотрудничества СССР с капиталистическими странами. - М., 1980. - 295 с.

14. Санников, А. Г. Совместные предприятия в СССР: опыт и проблемы / А. Г. Санников. - М. : ВНИИПИ, 1990. -53 с.

15. Смирнов, П. С. Совместные предприятия на территории СССР (правовое положение) / П. С. Смирнов // Внешняя торговля. - 1987. -№ 9. C. 50-54.

16. Смирнова, Е. Е. Совместные предприятия: закономерности возникновения и перспективы развития / Е. Е. Смирнова. - М. : Изд-во МГУ, 1988. - 163 с.

17. Яковенко, Е. Г. Совместные предприятия в СССР: опыт, проблемы, перспективы / Е. Г. Яковенко. - М. : ЦЭМИ, 1989. - 24 с.

\section{REFERENCES}

1. Bratchenko A. Sovmestnye predpriyatiya [Joint Ventures]. Moscow, Znanie Publ., 1989. 63 p.

2. Voznesenskaya N.N. Pravovye formy sovmestnogo predprinimatelstva i praktika SSSR [Legal Forms of Joint Enterprise and the Practice of the USSR]. Sovetskoe gosudarstvo i pravo [Soviet State and Law], 1985, no. 3, pp. 59-66.

3. Voznesenskaya N.N. Sovmestnye predpriyatiya s uchastiem firm kapitalisticheskikh i razvivayushchikhsya stran na territorii SSSR [Joint Ventures with the Participation of Firms in Capitalist and Developing Countries on the Territory of the USSR]. Sovetskoe gosudarstvo i pravo [Soviet State and Law], 1988, no. 1, pp. 117-125.

4. Zakon RSFSR «Ob inostrannykh investitsiyakh v RSFSR» ot 4 iyulya 1991 goda [The RSFSR Law "On Foreign Investments in the RSFSR" of July 4, 1991]. Vedomosti Syezda narodnykh deputatov RSFSR $i$ Verkhovnogo Soveta RSFSR, 1991, no. 29, art. 1008.

5. Zakon SSSR «O gosudarstvennom predpriyatii (obyedinenii)» ot 30 iyunya $1987 \mathrm{~g}$. [The USSR Law "On State Enterprise (Association)" of June 30, 1987]. Vedomosti Verkhovnogo Soveta USSR, 1987, no. 26 , art. 285.

6. Krasilnikova T.K. Administrativnaya reglamentatsiya organizatsii i deyatelnosti korporatsii i primenenie mer ugolovnykh repressii vSSSR v 20-e gody $X X$ veka [Administrative Regulation of the Organization and Activity of Corporations and Application of Measures of Criminal Repressions in the USSR in the 20s of the XX Century]. Vestnik Volgogradskogo gosudarstvennogo universiteta. Seriya 5, Yurisprudentsiya [Science Journal of Volgograd State University. Jurisprudence], 2012, no. 1 (16), pp. 53-56.
7. Krasilnikova T.K. Sovmestnoe predpriyatie $\mathrm{i}$ mezhdunarodnye khozyaistvennye obyedineniya $\mathrm{v}$ sisteme sovetskogo prava [Joint Venture and International Business Associations in the System of Soviet Law]. Obrazovanie i pravo [Education and Law], 2018, no. 12, pp. 78-83.

8. Mironov N.V. Pravovoy status sovmestnykh khozyaystvennykh organizatsiy stran - chlenov SEV na territorii SSSR [Legal Status of Joint Economic Organizations of the Countries - Members of the CMEA on the Territory of the USSR]. Sovetskoe gosudarstvo $i$ pravo [Soviet State and Law], 1984, no. 3, pp. 45-51.

9. Postanovlenie Prezidiuma VTsIK «O vneshney torgovle» ot 13 marta 1922 goda [Decree of the Presidium of the Central Executive Committee "On Foreign Trade" dated March 13, 1922]. SU RSFSR [SU RSFSR], 1922, no. 24.

10. Postanovlenie Soveta Ministrov SSSR ot 13 yanvarya 1987 g. № 48 «O poryadke sozdaniya na territorii SSSR i deyatelnosti sovmestnykh predpriyatiy, mezhdunarodnykh obyedineniy i organizatsiy SSSR i drugikh stran SEV» [Resolution of the Council of Ministers of the USSR of January 13, 1987, No. 48 "On the Procedure for Creating in the Territory of the USSR and Activities of Joint Ventures, International Associations and Organizations of the USSR and other CMEA Countries"]. SP SSSR [USSR JV], 1987, no. 8, art. 38 .

11. Postanovlenie Soveta Ministrov SSSR ot 13 yanvarya 1987 g. № 49 «O poryadke sozdaniya na territorii SSSR i deyatelnosti sovmestnykh predpriyatiy s uchastiem sovetskikh organizatsiy i firm kapitalisticheskikh i razvivaiushchikhsya stran» [Resolution of the Council of Ministers of the USSR dated January 13, 1987 No. 49 "On the Procedure for Creating in the USSR Territory and Activities of Joint Ventures with the Participation of Soviet Organizations and Firms of Capitalist and Developing Countries"]. SP SSSR [SP of the USSR], 1987, no. 9, art. 40.

12. Boguslavskiy M.M., Rubanov A.A., Slavin M.M., eds. Pravovoe polozhenie sovmestnykh predpriyatiy na territorii SSSR [The Legal Status of Joint Ventures in the USSR]. Moscow, Akademiya nauk SSSR, Institut gosudarstva i prava, 1988. $172 \mathrm{p}$.

13. Pravovye formy nauchno-tekhnicheskogo $i$ promyshlennogo sotrudnichestva SSSR s kapitalisticheskimi stranami [Legal Forms of Scientific, Technical and Industrial Cooperation of the USSR with Capitalist Countries]. Moscow, 1980. 295 p.

14. Sannikov A.G. Sovmestnye predpriyatiya $v$ SSSR: opyt i problemy [Joint Ventures in the USSR: Experience and Problems]. Moscow, VNIIPI, 1990. 53 p.

15. Smirnov P.S. Sovmestnye predpriyatiya na territorii SSSR (pravovoe polozhenie) [Joint Ventures in the USSR (Legal Status)]. Vneshnyaya torgovlya [International Trade], 1987, no. 9, pp. 50-54. 
16. Smirnova E.E. Sovmestnye predpriyatiya: zakonomernosti vozniknoveniya i perspektivy razvitiya [Joint Ventures: Patterns of Occurrence and Development Prospects]. Moscow, MGU Publ., 1988. 163 p.
17. Yakovenko E.G. Sovmestnye predpriyatiya v SSSR: opyt, problemy, perspektivy [Joint Ventures in the USSR: Experience, Problems, Prospects]. Moscow, TsEMI, 1989. $24 \mathrm{p}$.

\section{Information about the Author}

Tatiana K. Krasilnikova, Candidate of Sciences (Jurisprudence), Associate Professor, Department of Theory of Law and State Legal Disciplines, International Law Institute's Volzhsky Branch, Bolshevistskaya St., 7, 404106 Volzhsky, Russian Federation, kun_krasilnikova@mail.ru, https://orcid.org/ 0000-0002-5869-5859

\section{Информация об авторе}

Татьяна Константиновна Красильникова, кандидат юридических наук, доцент кафедры теории права и государственно-правовых дисциплин, Международный юридический институт (Волжский филиал), ул. Большевистская, 7, 404106 г. Волжский, Российская Федерация, kun_krasilnikova@mail.ru, https://orcid.org/0000-0002-5869-5859 